\title{
ALTERACIONES RELIGIOSAS EN EL NORTE DEL VIRREINATO PERUANO A FINALES DEL PROCESO DE EMANCIPACIÓN E INICIOS DE LA INDEPENDENCIA: EL PARTIDO DE PIURA
}

\author{
POR \\ RUth MAgal Rosas NAVARRO ${ }^{1}$ \\ Universidad de Piura
}

\section{RESUMEN}

En el aspecto religioso, el análisis histórico más recurrente del proceso de la independencia hispanoamericana ha sido el del grado de adhesión del clero al movimiento separatista, dejando de lado otros aspectos de repercusión social. Este artículo estudia las alteraciones experimentadas por los piuranos de 1819 a 1824, cuando se sella la independencia del Perú, en torno a eventos como el latrocinio de valiosos objetos de iglesias y cofradías, los múltiples donativos, destierros, encarcelamientos y levas, todos los cuales produjeron una situación de inseguridad y temor que influyó en el sentimiento patriótico y las ideas independentistas.

PALABRAS CLAVE: donativos; feligreses; independencia; leva; religiosidad.

\section{RELIGIOUS ALTERATIONS IN THE NORTH OF THE PERUVIAN VICEROYALTY AT THE END OF THE PROCESS OF EMANCIPATION AND THE BEGINNING OF INDEPENDENCE: THE PARTY OF PIURA}

\begin{abstract}
In the religious aspect, the most recurrent historical analysis of the process of Spanish-American independence has been the degree of adherence of the clergy to the separatist movement, leaving behind other aspects of social repercussion. This article studies the alterations experienced by the Piuranos from 1819 to 1824, when the independence of Peru was sealed around events such as the theft of valuable objects from churches and brotherhoods, the numerous donations, exile, imprisonment and levies which produced a situation of insecurity and fear that influenced patriotic sentiment and pro-independence ideas.
\end{abstract}

KEY WORDS: gifts; parishioners; independence; levy; religiosity.

Cómo CITAR ESTE ARTículo / CitATION: Rosas Navarro, Ruth Magali. 2019. «Alteraciones religiosas en el norte del virreinato peruano a finales del proceso de emancipación e inicios de la independencia: El partido de Piura». Hispania Sacra 71, 144: 629-640. https://doi.org/10.3989/hs.2019.045

$\begin{array}{ll}\text { Recibido/Received } & 17-04-2018 \\ \text { Aceptado/Accepted } & 10-10-2018\end{array}$

\section{Albores de LA independencia en el PARTido de PiURA}

Aunque en 1818 ya se había proclamado la independencia de algunas capitanías y virreinatos hispanoamericanos, continuaban en ellos los enfrentamientos entre realistas y patriotas, cada uno con motivaciones distintas que, desangraban lastimosamente a los dos bandos. En este contexto

\footnotetext{
1 ruth.rosas@udep.edu.pe / ORCID iD: https://orcid.org/0000-0002-6504-2469
}

sudamericano, el virreinato del Perú, entonces gobernado por el virrey Joaquín de la Pezuela Griñán, se tambaleaba. La expectativa creada por la victoria de los independentistas en Chile era tal, que el ámbito peruano se enrarecía lentamente, a causa del miedo y la vacilación, provocando que el virrey, temeroso de la revolución, tratara como prisioneros de guerra a los supuestos insurgentes detenidos, considerándolos rebeldes y traidores al rey (Mikhailovicht 1971: 170-171). 
El vicealmirante lord Thomas Cochrane, venido de Chile con el objetivo de apoyar la independencia del núcleo realista más poderoso en Sudamérica, atacó varios puertos de la costa norte y central del virreinato, trastocando aún más el ambiente. Entonces, el partido de Piura - perteneciente a la intendencia de Trujillo- contaba con dos puertos (Paita y Sechura) que se sumaban a otros tantos como Huanchaco, Casma, Huambacho, Supe y el Callao. En junio de 1818 , Cochrane apareció en el puerto de Sechura, donde sus soldados saquearon los templos apropiándose de varias alhajas de oro, plata, perlas y piedras preciosas. Haciendo de esto una mala costumbre, el 13 de abril del siguiente año llegaron al puerto de Paita, y contra todo pronóstico recibieron el apoyo de varios indios (chusma) que contribuyeron con el más grave despojo realizado por la escuadra de Cochrane (Barros 1999: 183). ${ }^{2}$ Los chilenos entraron en la iglesia de la Merced y en la iglesia matriz de Paita, extrayendo valiosos objetos como vasos sagrados que rodaron confundidos en el montón de despojos acumulados en aquellas horas turbulentas. Enfadado y avergonzado ante estos hechos, Cochrane hizo aprehender y azotar a los indisciplinados soldados frente a los espectadores que se dieron cita en la plaza pública, devolviendo, en la medida de lo posible, lo robado e indemnizando a los clérigos con mil pesos por el daño causado (Barros 1999: 183). Estos funestos sucesos generaron temor entre los piuranos, así como el rechazo a la expedición que pasó a ser conocida como la de "los enemigos de Chile», y no como la de unos libertadores (Hernández 2005: 349).

Cabe aquí preguntarse el porqué de la actuación de los indios paiteños que apoyaron el saqueo chileno. Las respuestas se circunscriben en un conjunto de causales: el hartazgo de los pobladores ante los castigos corporales; la sistemática exigencia tributaria de las autoridades políticoreligiosas; la multiplicidad de pagos y ofrendas a cambio de misas, sacramentos, bulas y entierros; y, por último, la euforia de experimentar autonomía y libertad para robar bienes de la iglesia o parroquia. Con todo, lo que provocaron los soldados, a mediano plazo, es que se expandiera la noticia y que los demás pueblos sintieran cierto temor y rechazo por esta tropa chilena. Su presencia, padecida durante varios meses, paralizó el comercio y, por supuesto, generó rogativas públicas y oraciones privadas dirigidas al Todopoderoso, a la Virgen y a los santos, a quienes se imploraba alejarlos lo más posible. Cuando estos llegaron a Supe con la intención de pasar luego a Trujillo, los feligreses, aprovechando el novenario de Nuestra Señora del Socorro, realizado cada cinco años, rogaron por la liberación de esa funesta presencia. Su subsiguiente éxito fue agradecido fervorosamente, ${ }^{3}$ asumiendo que la Virgen les había concedido el milagro y cimentado así la fe de los trujillanos.

Entre tanto, José Bernardo de Tagle, asumía el cargo de intendente de Trujillo en agosto de 1820. Un mes después, en Lima se proclamó y juró la constitución española y, a

2 Los documentos relativos a la toma de Paita (parte dado por Cochrane desde la bahía del Callao, proclama y oficio a la autoridad eclesiástica del puerto) fueron publicados en el número extraordinario de 9 de agosto de la Gaceta ministerial y también en la Gaceta de Buenos Aires. Algunos datos aparecen en el Diario de Álvarez Jonte.

3 Cfr. Archivo General de la Nación (AGN). Colección Tomás Diéguez (CTD). Caja 3, cuaderno № 10, carta 36, Trujillo, 1820, fol. 55. los pocos días - 20 de setiembre- San Martín y su ejército patriota desembarcaban en Pisco, obligando al virrey Pezuela a reorganizar el ejército realista. La situación interesa sobremanera porque el peligro derivado de tales sucesos originó en los pobladores manifestaciones religiosas que imploraban el auxilio de Dios y el fin de las muertes de civiles y militares. Asimismo, porque incitó a muchos vecinos a huir a Cajamarca, hacia donde remitieron también «la plata labrada de la Catedral [de Trujillo], ornamentos y colgaduras» porque se asumía que, en caso de invasión, ese lugar sería el punto de defensa. ${ }^{4}$

La dinámica de los hechos fue tan sorpresiva que no dio tiempo a la jerarquía eclesiástica para planificar y ejecutar una estrategia conjunta respecto de la independencia. Es, por lo tanto, entendible que los sacerdotes y religiosos de una misma diócesis tuvieran diferentes opiniones que los llevaron a aceptar o rechazar la libertad política y, por ende, a querer imponer esta opción o convencer de ella a la mayoría de sus feligreses, ya desde el púlpito, el confesionario o la simple conversación amistosa.

Algunos sacerdotes de la serranía piurana, aprovechando su lejanía de la capital de la provincia y guiados por sus convicciones patrióticas, utilizaron el púlpito en las celebraciones dominicales y festivas entre sus "hermanos compatriotas, exhortando y predicando $»^{5}$ por la causa emancipadora cuanto estuviera a su alcance. En Amotape, por ejemplo, el cura José Mercedes Espinosa sería uno de los primeros en asumir la causa patriota, incluso antes de proclamada la independencia en el partido, trabajando ocultamente «contra el empeño de los disidentes» realistas lo que le valdría tres denuncias ante la autoridad. Dicho párroco recalcó que durante más de quince años había administrado el curato de «Huancabamba, Yapatera, Guarmaca, Congoña y Amotape [...] sin dar qe decir ni qe se me haya notado falta en el cumplimiento de mi ministerio [...] con honrrosidad y libre de crímenes qe acrediten lo contrario». ${ }^{6}$ Destacó su acendrado patriotismo expresándolo abiertamente en una serie de proclamas independentistas sabiendo que esto podía acarrearle consecuencias negativas como el que lo hubiesen tildado de «insurgente». Movido y lleno de fervor patriótico aprovechó cada ocasión para extender dichas ideas entre los habitantes de su feligresía a pesar de que esto significara el odio de los realistas contra su persona. ${ }^{7}$ Es de suponer la rapidez de la expansión de las ideas independentistas, sobre todo por la disconformidad que existía con los castigos físicos, diezmos, bulas y otras imposiciones, frecuente origen de revueltas según hemos destacado en la tesis denominada «Religiosidad en el Partido de Piura durante el proceso de independencia. 1780-1821».

La prédica, a favor o en contra de la independencia, generó incertidumbre entre los oyentes, que, en familia o en círculos amicales, discutían los pormenores de los últimos acontecimientos y lo beneficioso o negativo que podía resultar el nuevo orden político. Centrándonos en la independencia del norte del virreinato peruano, el marqués de Torre Tagle proclamó la independencia en Trujillo el 29 de

4 Cfr. AGN. CTD. Caja 3, cuaderno № 10, carta 34, Trujillo, 1820, fol. 50-52.

5 AGN. CTD. Caja 2, cuaderno № 6, carta 15, Amotape, 1822, fol. 1.

6 Ibídem.

Ibídem. 
diciembre de 1820. Desde entonces la emancipación de los otros partidos fue cuestión de semanas, efecto de la convicción que iban adquiriendo o bien de la presión militar ejercida por el citado marqués.

Piura proclamó la independencia el 4 de enero de 1821, sin derramamiento de sangre y sin la participación del clero. Sobre los pormenores del proceso ya hemos hablado en otro documento (Rosas 2013: 149-151); por tanto, toca ahora analizar el aspecto religioso manifestado durante $y$ después de lograda la emancipación.

La alegría y celebración a que se entregaron los piuranos fueron grandes y duraron hasta el 6 de enero, fiesta de Reyes Magos, cuando se juró la independencia, saludada con veintiún cañonazos y con una misa de acción de gracias, solemnizada con Te Deum (Gutiérrez 2004: 360). No se conservan documentos que describan la prédica de aquella misa, pero intuimos que debió estar llena de ideas separatistas y rogativas a Dios por bendiciones en ese nuevo rumbo político.

Según afirma Julissa Gutiérrez, en los días posteriores, los distintos poblados del partido, tanto de costa como de sierra, se sumaron a la independencia; el clero, sin embargo, no se pronunció a favor de la libertad. Por este motivo, el gobernador eclesiástico Gamboa envió el 13 de enero al vicario de Piura, Tomás Diéguez, un oficio en el que le ordenaba jurar la independencia, firmar el acta y celebrar misa con Te Deum. Al poco tiempo, viendo el vicario que todo estaba perdido para el dominio español en esta región, juró por Dios y los Santos Evangelios defender la independencia de América, sostener los derechos de la patria y contribuir con ambos objetivos; asimismo, guardar obediencia a las autoridades legítimamente constituidas. Efectuado este juramento, en la iglesia matriz, hizo lo propio el cura rector de esta seguido por los demás eclesiásticos (2004: 364-365). No obstante, no todos los miembros del clero acataron este mandato con la misma rapidez dada la fuerte ambigüedad que tenían los planteamientos realistas e independentistas: los franciscanos, por ejemplo, excusaron su juramento ante la falta de órdenes superiores venidas de Lima, pues tenían noticias de que allá sus hermanos se habían opuesto a la independencia al relacionarla directamente con la constitución liberal española de entonces, que en sus artículos atacaba, según decían, a los miembros de la Iglesia. Los franciscanos asentados en Lima pronunciaron sermones con argumentos contrarios al sistema republicano y utilizaron todos los medios a su disposición para reforzar dicha oposición, llegando incluso a reservarse la absolución de los pecados si el feligrés respondía que aceptaba la Constitución. Es de suponer una actitud parecida en los demás franciscanos apostados en las principales ciudades como Piura; de ahí su oposición a jurar la independencia como demostró, por escrito, el R. P. guardián Miranda, europeo, que tratando de justificarse delató al canónigo electo de la iglesia de Cuenca, Andrés Villamagán, y al R. P. fray Francisco Javier Granda, de la orden de san Agustín, también de Cuenca, por negarse a prestar el juramento de independencia de la América proclamada en esta provincia. ${ }^{8}$

Ante esta actitud, el vicario Tomás Diéguez -ya en el bando de los patriotas - comprobó personalmente la

\footnotetext{
8 Cfr. AGN. CTD2. Nueva signatura. Caja 1. Doc. 22. «Carta de Tomás Diéguez a Cleto Gamboa». Feb. 1821, fol. 1r-v.
}

fidelidad de los miembros de conventos e iglesias, observando el juramento realizado por los tres conventos de la ciudad (franciscano, mercedario y betlemita) del 25 al 28 de enero, y las iglesias de Sechura y Querecotillo el 12 de febrero (Ramos 1973: 29-30). Solo unos pocos, como el presbítero Manuel García, no pudieron expresar su separatismo por encontrarse en Trujillo postulando a alguna prebenda, lo que indujo al vicario a ordenar su regreso «para que hagan la bendición de causa y lleven su ministerio en la Cuaresma próxima». ${ }^{9}$

Cabe advertir que el juramento logrado por el clero no era síntoma de adhesión por convicción, considerando que respondían a las exigencias del vicario, dado el contexto convulso en el que vivían que no les permitía arriesgarse a desobedecer órdenes de su superior. Asimismo, es probable que como miembros de la Iglesia no quisieran mezclarse en asuntos políticos, orientando su labor a la evangelización y administración de culto, resguardando así sus beneficios económicos.

\section{PROCLAMACIÓN DE LA INDEPENDENCIA EN LA CAPITAL DEL VIRREINATO PERUANO}

Mientras que el norte del Perú se emancipaba, la capital permanecía bajo el dominio del virrey José de La Serna quien no dudó en agenciarse de bienes materiales que permitieran solventar los gastos del ejército realista. Para tal fin, usó la plata labrada de las iglesias justificando tal acción con la idea de que dichos objetos destinados al culto divino no debían «conservarse para que la rapacidad de los enemigos la emplee en su ofensa» (Vargas 1945: 175). Esta apropiación del patrimonio de la iglesia se realizaría en varias ocasiones generando el reclamo del obispo de Lima, Bartolomé María de las Heras, de haber entregado casi todo, aduciendo que en la Matriz se habían extraído hasta las andas de plata, lo que impedía la celebración de procesiones (Vargas 1945: 176-177). Con esto se corrobora que algunas medidas del gobierno afectaron directamente la manifestación de la religiosidad del feligrés, pues impedían la realización de las fiestas que mandaba el calendario litúrgico y eliminaban el momento propicio para rendir culto a Dios y a los santos en momentos tan difíciles.

El 28 de julio de 1821, día de la proclamación de la independencia en Lima, la Gaceta del Gobierno criticó duramente un proyecto de concordato aprobado por las Cortes de España que secularizaba las instituciones religiosas y que, entre otras cosas, suprimía las festividades de los santos. En síntesis, la censura decía: «iGracias a Dios que ya no pertenecemos a semejante nación! La religión va a refugiarse en nuestros países, esto solo bastaría para justificar la Independencia que proclamamos hoy...» (Bonilla 2001: 33).

Con esta idea fundamentaban, con argumentos religiosos, el haberse emancipado de una nación que empezaban a considerar sacrílega por las medidas que habían establecido contra la Iglesia, lo cual refuerza la paradoja de que los franciscanos realistas de Lima temieran a la constitución por impía y los patriotas del Perú también; y que cada uno justificara su causa en esa impiedad. El robo de objetos de oro

\footnotetext{
9 AGN. CTD. Nueva signatura. Caja 1. Doc. 23. "Carta de Tomas
} Diéguez». Feb. 1821, fol. 1r. 
y plata de las iglesias por parte del virrey, sumado a la intrusión del gobierno español en el ámbito religioso y a otros elementos, sustentaron sobradamente los actos independentistas que se vivieron entonces.

Tal fue el impacto de estas noticias que, a decir del historiador Armando Nieto, los clérigos regulares empezaron a apoyar la emancipación por el rumor de que el gobierno español iba a suprimir la mayor parte de los conventos, quedando los restantes sin privilegios ni exención, sujetos al ordinario diocesano. Al parecer aquí radicaba la verdadera razón de que en sus prédicas, escritos y conversaciones particulares "clamasen contra el gobierno de la Península y aun animasen a las gentes a que admitiesen con placer la entrada en Lima del General San Martín» (Nieto 1969-1971: 370-371).

Por el contrario, en algunas ciudades como Trujillo se desataron actos violentos entre la población y la tropa patriota, dejando como saldo varios muertos. La euforia y violencia a que se entregaba parte de la tropa disminuyó su respeto por la vida humana y atrajo la desgracia sobre muchos presuntos partidarios del sistema colonial. Así, en julio de 1821 los trujillanos fueron testigos de varios asesinatos de curas fruto del desquiciamiento:

El primero fue un Don N. Gusman qe asomándose por una ventana del alto de su avitacion al tiempo de entrar la tropa en el pueblo, le dispararon un fusil, figurándose fuese alguna emboscada, y quedó muerto; y el segundo, se apellida Yupanque el cual murió dentro de la Yglesia con otros muchos seglares por medio de las balas qe disparó la tropa. También se dice qe falleció otro eclesiástico [...] que hacía de capellán a los realistas, aunque de este no se sabe su paradero [...] lo más probable es que haya huido. ${ }^{10}$

Como observamos, a pesar de haberse declarado la autonomía política se suscitaron actos violentos lo que además de muerte e incertidumbre originó miedos, huidas y renuncias entre los miembros del clero. En septiembre de 1821, por ejemplo, el obispo Las Heras, presionado por el ministro de San Martín, Bernardo de Monteagudo, dejó el cargo. Este recayó interinamente en el deán Francisco Javier Echagüe, quien tendría que afrontar momentos difíciles hasta que se consiguió sellar la independencia del Perú en 1826. Igualmente renunciaron los obispos de Trujillo y de Huamanga.

\section{PRESENCIA DEL EJÉRCITO PATRIOTA EN PIURA Y SU IMPACTO EN LA RELIGIOSIDAD (1821-1823)}

La incertidumbre era tal en los meses posteriores a la proclamación de la independencia que los mismos eclesiásticos se enfrentaron entre sí por los beneficios que unos tenían desde años anteriores y que asumían habían perdido con la República, afectando directamente al grupo de parroquianos que estaba a su cargo y dejándolo sin ceremonias litúrgicas ni fiestas religiosas.

En Amotape, por ejemplo, el presbítero patriota José Mercedes Espinosa era dueño de una hacienda ubicada en la doctrina de la Huaca y cercana a la capilla del Arenal. Necesitando en algunas estaciones del año residir en ella,

10 AGN. CTD. Nueva signatura. Caja 2. Doc. 422. «Carta de Fernando a Tomas Diéguez». Jul. 1821, fol. 1ss. aprovechaba su estadía para celebrar misa y fiestas en cualquiera de sus iglesias por las licencias refrendadas por el Provisor. Sin embargo, en setiembre de 1821, el cura Manuel Santiago Adrianzén le negó dicho privilegio, recogiendo la llave del templo e impidiendo cualquier celebración ritual en ninguno de los demás anejos de su doctrina. Ante tal situación, Espinosa se regresó a Amotape, acompañado de algunos vecinos españoles

\begin{abstract}
atravesando el río [...] con mil incomodidades y a más de las doce del día por no quedarnos sin decir misa, como aconteció, no la oyeron todos los habitantes de dicha capilla por la negación que nos hiso su cura [...] que además no la podía ministrar por la distancia en que reside de su Doctrina de la Huaca. ${ }^{11}$
\end{abstract}

Hace saber del funesto episodio al vicario Tomás Diéguez, a modo de reclamo, logrando que este envíe al cura de la Huaca una misiva en la que recomienda no impida sino más bien franquee la iglesia del Arenal y demás curatos al mencionado presbítero Espinosa, sin perjuicio de sus derechos parroquiales. ${ }^{12} \mathrm{El}$ beneficio con que contaba dicho presbítero se mantuvo aún después de la independencia, y mucho más cuando había demostrado su acendrado patriotismo en varias oportunidades, no solo con el vicario sino sobre todo con las altas esferas de la jerarquía eclesiástica de Trujillo, a quien continuó informando de los pormenores religiosos de su curato. Así, en octubre, denunció al padre guardián del convento de San Francisco de Piura, porque en una misa cantada omitió la Colecta et famulos tuos por la que se pedía «por el Papa, el Obispo, el Rey y sus familiares, el virrey y otras súplicas, como la confirmación de los indios a la fe católica, la paz, la salud... etc.». ${ }^{13}$ En lo que va de la investigación no hemos encontrado la causa de tal omisión pero intuimos que, como aún las tropas realistas permanecían en territorio peruano se tenía alguna esperanza de volver al Antiguo Régimen y, por ello, el obispo de Trujillo José Carrión y Marfil enterado del suceso, de inmediato envió misivas al vicario Diéguez en las que pedía indague sobre el asunto y verifique dicho desorden, tras lo cual debía pedir "fraternal y amistosamente la causa que le induce, previniéndole que de no sujetarse a lo mandado, usara de las facultades de su oficion. ${ }^{14}$

Otro curato en el que se experimentaron breves desequilibrios fue Catacaos, sobre todo después de la salida para Lima del vicario Diéguez, porque se hizo difícil conseguir reemplazo para el encargado que este había dejado. La ausencia de autoridades religiosas contribuyó entonces a un mayor desorden, que ni siquiera pudo solucionarse por la escasez de curas y de dinero para sufragarles sus tercias y demás derechos. ${ }^{15}$ Se había entrado en un círculo vicioso en el que se agudizaba aún más el descuido y abandono del adoctrinamiento y de la celebración de misas, sacramentos y entierros, la falta de ofrendas, diezmos y bulas y

11 AGN. CTD. Nueva signatura. Caja 1. Doc. 52. «Carta de Jose Mercedes Espinosa a Tomas Diéguez». Set. 1821, fol. 1ss.

12 AGN. CTD. Nueva signatura. Caja 1. Doc. 52. «Carta de Jose Mercedes Espinosa a Tomas Diéguez». Set. 1821, fol. 1v.

13 Archivo General de Indias (AGI). Lima 522 (cursiva añadida).

14 AGN. CTD. Nueva signatura. Caja 2. Doc. 673. "Carta de Gamboa a Tomas Diéguez». Oct. 1821, fol. 1 r.

15 AGN. CTD. Nueva signatura. Caja 4. Doc. 1448. "Carta de Fermín Seminario a Tomas Diéguez». Oct. 1822, fol. 1ss. 
el descontento de los ministros religiosos que optaron por ausentarse. Aunque esta situación fue común en casi todo el virreinato peruano durante los siglos XVII y XVIII (sobre todo en zona rural) hemos de recalcar que, tras la declaración de la independencia, la labor realizada por algunos sacerdotes y religiosos se tornó más profana afectando directamente las distintas manifestaciones religiosas de los feligreses.

La disconformidad con la independencia, el miedo al temperamento belicoso de la feligresía, el temor ante las medidas perjudiciales del nuevo gobierno y la falta de pagos fueron las principales causas por las que algunos pastores continuaron con el abandono de sus ovejas y otros tantos modificaron su labor pastoral. A estas razones se suma el ya mencionado interés por presentarse a la diócesis de Trujillo para competir por un curato o cargo eclesiástico, lo que implicaba quedarse varias semanas en esta ciudad o en poblados aledaños; el padecer alguna enfermedad, por ancianidad u otras causas y residir en lugares propicios para la recuperación de la salud por varias semanas o meses (sobre todo en ciudades); y el atender negocios políticos o económicos en otros lugares. Estas razones, expresadas en múltiples misivas, tratan de justificar ausencias de los curatos o solicitar traslados a otras parroquias, tal como lo hizo José Manuel del Carmen Arana, cura de Yapatera, en 1822, cuando pidió traslado de su curato porque el ambiente no le era propicio pues, a diario echaba «sangre por la boca, con una continua calentura y [...] un grande y hermoso baso qe he adquirido qe se me inflama y qe aveces me impide [...] el montar a bestia para el cumplimiento de mis obligaciones». ${ }^{16}$

Otro licenciado que había abandonado su feligresía, desde antes de proclamada la independencia, fue Mariano Donato Guzmán Portocarrero, ayudante de Tadeo Celis en la doctrina de Huancabamba. Dicha ausencia obligó al anciano Tadeo a solicitar al vicario dos sacerdotes — con la congrua de 200 pesos libres de gravamen de misas a cada uno- para que le ayuden con los ministerios parroquiales ${ }^{17}$ mientras esperaba el regreso de su ayudante tras su postulación a una prebenda en Trujillo. El vicario Tomás Diéguez designó solo al eclesiástico Saavedra para ese curato, por lo que Celis insistió en que necesitaba de alguien más porque era difícil atender una "parroquia tan lata» en la que vivía "con repugnancia» ya que estaba rodeado de "gente brutal». ${ }^{18}$ Este comentario se entiende porque esta y otras comunidades se caracterizaban por su carácter impulsivo y rebelde, reconocido en toda la provincia. En este caso se observa la conjugación de tres causas: el presentarse como candidato para un curato por parte del inter de cura, la vejez del sacerdote principal y, sobre todo, el carácter poco dócil de los feligreses. Al respecto, ya Joaquín Helguero, desde inicios del siglo XIX, aseveró que los indios huancabambinos no solo eran de carácter flojo, sino también "revoltosos» pues se ocupaban en "fomentar motines y asonadas que atemorizaban" a hacendados y por supuesto a sacerdotes (Helguero 1984: 36).

16 AGN. CTD. Nueva signatura. Caja 1. Doc. 66. «Carta de Josef Manuel del Carmen Arana a Tomas Diéguez». Jun. 1822, fol. 1r.

17 AGN. CTD. Nueva signatura. Libro 11. Cuaderno 34. Carta 48. «Carta del doctor Machado a Tomas Diéguez». Jul. 1820, fol. 1ss.

18 AGN. CTD. Nueva signatura. Caja 1. Doc. 155. «Carta de Tadeo Celis a Tomas Diéguez». Set. 1820, fol. 1v-2v.
Tadeo Celi aprovechó la comunicación con el vicario Diéguez para implorarle, en un primer momento, que lo saque de ese curato para colocarlo «en un rinconcillo fácil de servirse», pues hallándose en el último tercio de su «vida llena de intercadencias muchas por mi culpa, ya se ve, pero no pocas por las agenas $"{ }^{19}$ pide encarecidamente ese favor, aunque, tras reflexionar sobre el asunto, especifica que no desea ser trasladado a Piura porque le parece una provincia belicosa y polvorienta:

Yo acá [dice Tadeo] vivo más lejos y, por lo tanto, con menos peligro de caer en manos y voca de insurgentes públicos y secretos o de que me traten como a tal. Finalmente no envidio la situación de V [...] De dia en dia se va aumentando el ruido Constitucional. Creo que si Yo hubiera sido el Monarca de las Españas, primero que firmar la Constitución, hubiera dicho lo que el último General de los Jesuitas: 'O bien seamos como somos o no seamos. ${ }^{20}$

Como verificamos, por más de un año Piura tuvo que afrontar la movilidad de sacerdotes que huían de sus parroquias por múltiples motivos y que a su vez provocaban el que otros pidieran algunos de los curatos vacíos, dejando totalmente abandonados los menos rentables. El tema monetario fue una causal importante, pues casi siempre se buscaba la opción que generara mayores ingresos para poder atender a los familiares directos o cercanos. En noviembre de 1821, por ejemplo, al enterarse de que había renunciado el cura de Ayabaca, Eusebio Carnero pide a Tomás Diéguez que lo traslade a ese curato, argumentando que lleva el gravísimo peso de su pobre madre viuda, dos hermanitas y cuatro hermanos menores, a quienes mantiene con dificultad pues no le alcanza con los doscientos pesos anuales que percibe. ${ }^{21}$

Por otro lado, la ausencia de sacerdote también estaba relacionada directamente con el abandono del templo y la situación empeoraba si este se ubicaba en la sierra (zona rural) o en un poblado costeño alejado de la ciudad de Piura; pues, al no poder celebrar misas y, por ende, no percibir ofrendas de ningún tipo, no podían contar con el porcentaje destinado a la "fábrica» de la iglesia ni mucho menos mantenerla en buen estado de limpieza. Cuando, al cabo de varios meses, llegaba el reemplazo, se encontraba con un escenario lamentable, tal sucedió en Tumbes, en 1822, al cura José Antonio Sierra, quien inmediatamente informó al vicario Diéguez del absoluto abandono en que estaba esta iglesia, en la que no había «ni Ara en que decir Misa, pues solo encontré un pedazo de lo que fue alguna vez Ara».22 Corroboramos, nuevamente, que sin la presencia de autoridades eclesiásticas en los pueblos, los feligreses, poco adoctrinados, desatendían totalmente cualquier práctica de la religión cristiana.

Con todo, este proceder de absentismo observado en varios eclesiásticos provocó que se tambaleara la estructura de la Iglesia y que los feligreses imbuidos de ideas liberales continuaran rehusándose a la adquisición de las distintas bulas y a la entrega de la limosna para los Santos Lugares

19 AGN. CTD. Caja 1. Doc. 155. "Carta de Tadeo Celis a Tomas Diéguez». Set. 1820, fol. 1v-2v.

20 Ibídem.

21 AGN. CTD. Nueva signatura. Caja 1. Doc. 216. «Carta de Eusebio Carnero a Tomas Diéguez». Nov. 1821, fol. 1r.

22 AGN. CTD. Caja 4. Doc. 1461, Tumbes, 1822, s/fol. 
de Jerusalén. Esta actitud de los parroquianos suscitó la desesperación de varios sacerdotes, quienes, a pesar de la prohibición, ${ }^{23}$ continuaron infligiendo castigos corporales a los indios con el fin de adoctrinarlos. Las quejas de los feligreses, entre otras cosas, por la violencia ejercida contra ellos, continuaron llegando al despacho del obispado de Trujillo en 1822. Desde allí, el encargado reitera al vicario de Catacaos, Tomás Diéguez, que se utilicen otros medios de persuasión con ellos, como la prédica y el ruego, para que cumplan con sus deberes, y se eviten los azotes y la cárcel. ${ }^{24}$

Las bulas, cédulas o sumarios que debían ser adquiridos por los penitentes antes de confesarse y comulgar fueron desde siempre un elemento rechazado por los parroquianos, porque, por un lado, se les exigía su compra - cuestión que no siempre podían hacer por falta de dinero-y por otro, recibían castigos físicos si desaprovechaban las gracias e indulgencias que los sacramentos otorgaban. Para llevar una contabilidad exacta de las cédulas, se tuvieron en cuenta los padrones de los feligreses de cada curato con sus respectivas edades y clases. También, a partir de la visita de José Antonio de Areche a las principales ciudades del virreinato peruano en 1783 , se analizó el monto pagado, estableciéndose uno que tuviese relación directamente proporcional con la posición político-social y, sobre todo, con el patrimonio monetario de cada cual.

Teniendo en cuenta lo dicho, en Piura y en el resto del virreinato se repartía a cada sacerdote bulas de vivos, de difuntos, de carnes y lacticinios y de composición. Por este trabajo de repartimiento de bulas los curas recibían el 4 $\%$ del valor total expendido; mientras que los vicarios que tenían el cargo de comisarios de cruzada, además de este porcentaje, recogían un $2 \%$ del producto total del curato. Para ambos casos, este monto estimulaba el empeño de los sacerdotes en entregar las cédulas a sus feligreses y enviar el dinero al encargado, porque de lo contrario lo restarían de su salario o estipendio, que quedaba como garantía. ${ }^{25}$ Así había funcionado el sistema antes de la independencia y así pretendían los sacerdotes que siguiera desarrollándose, sin tener en cuenta que, con los aires emancipadores, los fieles se rehusarían aún más a comprarlas. En la feligresía de Huarmaca, por ejemplo, en enero de 1822 , se solicitaron 600 bulas y cuatro meses después no se habían vendido ni cien, porque «ni el Teniente ni el común de yndios las habían sacado", a pesar de las amonestaciones que daba el cura en la misa dominical y en fiestas. Dicho cura, Carlos Cáceres, advertía en una carta al vicario Diéguez que «si no fuera por 100 que se llevó el Sr. Cura de Congoña y los pocos blancos del pueblo, todavía estarían íntegras» ${ }^{26}$ Observemos que ni siquiera la Semana Santa había propiciado la adquisición de las bulas. Si, ya antes de la independencia, la resistencia de

23 El 28 de mayo de 1820, en plena efervescencia de la Constitución española, se prohibió la pena de azotes extendiéndola a los párrocos doctrineros, casas de corrección, seminarios, escuelas y demás establecimientos públicos. Cfr. AGN. CTD. Nueva signatura. Caja 1. Doc. 22 "Carta del Obispo José Carrión y Marfil a Tomás Diéguez». Nov. 1820, fol. $1 r$.

24 AGN. CTD. Caja 1, correspondencia n.o 4, carta 2, Trujillo, 1822, fol. 1.

25 AGI. Lima. 1616. N. 407. Propuesta enviada por el Visitador Areche a su Magestad. May. 1782.

${ }^{26}$ AGN. CTD. Caja 2, correspondencia n. 8, carta 10, Huarmaca, 1822, fol. 1v. la población indígena a adquirirlas era evidente, esta se hizo mayor en los años posteriores.

Con respecto a la negativa a contribuir con las limosnas para los Santos Lugares de Jerusalén, se manifestó también en otros espacios próximos al partido, pues desde Lima, por ejemplo, se enviaron órdenes para que se evitara la propagación de esta actitud. También desde Trujillo, el ya mencionado Gamboa advirtió a Diéguez que procurara predicar en las doctrinas y curatos en contra de esta «impía negación», evitando el perjuicio de los Santos Lugares por la falta de dinero y las quejas del padre comisario. ${ }^{27}$

Vamos al meollo del asunto. Con la presencia del Ejército Libertador en territorio peruano y la organización de las tropas patriotas, el gobernador realista, militar y político de Lima, Pedro José de Zárate, hubo de adoptar medidas urgentes. Una que alteró la vida religiosa de la ciudad, promulgada el 10 de julio de 1821, fue la prohibición del tránsito a todo individuo a partir de las siete de la noche. Quien la desobedeciera podría ser castigado severamente e incluso fusilado por las patrullas rondantes. ${ }^{28}$ Esta medida es entendible en un contexto en el que realistas y patriotas buscaban lograr sus objetivos políticos aún a costa de trastocar la religiosidad de los parroquianos. Los limeños vivieron esto en carne propia, pues no podían celebrar procesiones o fiestas religiosas nocturnas, ni tampoco velaciones fúnebres, septenarios, novenarios o responsos después de anochecer.

En el intento de los patriotas por mantener y expandir la independencia a todos los rincones del virreinato peruano, se aplicó un constante incremento de contribuciones personales e institucionales. Este objetivo conllevó tanto el aporte económico (bienes materiales, dinero, alhajas, objetos de oro y plata, etc.) como el reclutamiento de hombres para engrosar las filas del ejército. Estímulo para no contribuir fue, a menudo, el deseo de conservar los bienes personales o la misma vida.

Una de las primeras medidas militares asumidas en Piura fue el reclutamiento de varones que debían defender la independencia o tratar de extenderla a los pueblos aledaños. Esta primera acción alteró los ánimos de las familias cuyos miembros fueron requeridos, porque habían asumido que, con su mero apoyo a la declaración de la autonomía política, quedaban eximidos de poner en peligro sus vidas en campaña. Los pocos que se salvaron de la leva fueron aquellos que presentaron dolencias o enfermedades, aunque les quedó el desasosiego de que apenas recobraran la salud tendrían que presentarse ante la autoridad militar. Numerosas quejas circularon por varios medios, como la de Manuel Diéguez, quien al referir la enfermedad de su hermano Fernando declara que no entiende, en ese ambiente de confusión, cómo «los más honrados sean los que sufran vejámenes después de que han corrido los riesgos que los hicieron libres». Para los "bribones» que quieren enrolar a su hermano e injurian al mismo vicario Tomás, pide el mayor castigo. $^{29}$

27 AGN. CTD. Caja 1, correspondencia n.o 4, carta 2, Trujillo, 1822, fol. 1.

28 Cfr. AGI. Lima 800. Colección de los Bandos publicados por el Gobierno de Lima Independiente. Imprenta del Río, Lima, 10 de julio de 1821, p. 4.

${ }_{29}$ Cfr. AGN. CTD. Nueva signatura. Caja 1. Doc. 458, «Carta de Manuel a Tomás Diéguez». Mar. 1821, fol. 1r-v. 
Poco después, antes de evacuar la ciudad de Lima con su ejército (6 de julio de 1821) para dirigirse a la sierra, el nuevo virrey La Serna agrupó a enfermos y cansados y los refugió en la iglesia dirigida por el presbítero José lldefonso Palacios, con el pretexto de convertirla en un hospital provisorio. Sin embargo, a las pocas horas ordenó cerrar todas las entradas y prender fuego a dicho templo. Justificó esta atrocidad como un modo de prevenir que, cuando hubieran sanado, se pasaran al bando contrario. Igual motivo alegó para fusilar, durante su marcha hacia los Andes, a todo aquel que mostrara cansancio en la retirada. ${ }^{30}$ La noticia de estos crímenes se difundió por el territorio e incrementó el temor a las tropas realistas. Por otra parte, el miedo a los patriotas aumentó cuando San Martín, tras proclamar la independencia, emite órdenes precisas para el reclutamiento de varones, recalcando que los solteros, de 16 a 40 años, debían enrolarse en el ejército durante ocho meses, después de lo cual se les daría licencia para retirarse a su casa. De esto quedaron exceptuados, en un primer momento, los funcionarios y empleados públicos, los hijos de viudas, el mayor de padres septuagenarios, los propietarios de haciendas y de tienda abierta y los maestros de oficios. ${ }^{31}$ Sin embargo, a medida que pasaron los meses, cuando se hacía más difícil la erradicación final de las tropas realistas, la orden se sintetizó en «que los europeos solteros salgan al Exército [...] y los casados den fianzas y a proporción de sus facultades un donativo forzoso". ${ }^{32}$ De este modo se garantizaba el rechazo al ejército realista asentado en la serranía del virreinato y, por otra parte, se generaban los recursos necesarios para la manutención de la tropa patriota.

Las cosas empeoraron para los habitantes del partido piurano cuando, en agosto de 1822, el coronel Manuel Rojas, rioplatense, asumió el poder político y militar de Piura. En este puesto recibió de la Comisión de Guerra la orden de incrementar sus tropas con tres mil soldados de todo el departamento de Trujillo, ardua tarea que le llevaría a cometer excesos contra la población, para quien se ganó fama de gobernante arbitrario y tiránico.

Durante su estadía en Piura, Catacaos y Paita, Rojas aplicó un riguroso reclutamiento de solteros y casados «llevándose con engaños hasta los cívicos» y dejando despoblada la ciudad, "llena de lamentos y llantos», pues a más de 160 civiles los embarcó para la capital. ${ }^{33}$ Esta medida de orden militar interesa en nuestra investigación porque está íntimamente relacionada con el aspecto religioso: Rojas aprovechaba, principalmente, los domingos y fiestas religiosas para enrolar civiles al ejército. Los pormenores de esta medida circulaban rápidamente por los lugares aledaños, de manera que el 2 de noviembre, los fieles que celebraban en Catacaos la festividad de Todos los Santos, abandonaron la iglesia temerosos de ser capturados y dejaron a medias la celebración de misa y fiesta. Este episodio provocó las

30 Cfr. AGN. CTD. Nueva signatura. Caja 3. Doc. 1248. «Carta de José Ildefonso Palacios a Tomas Diéguez». Ago. 1821, fol. 1r-v.

31 Cfr. AGI. Lima 800. Colección de los Bandos publicados... 31 de julio de 1821, p. 23.

32 AGN. CTD. Caja 3, correspondencia n. 11, carta 26, Piura, 1821 fol. 34 .

33 AGN. CTD. Caja 4, doc. 1449, Catacaos, 1822, fol. 21-22. Véase también en Caja 3. Doc. 1387. «Carta de José Romero a Tomás Diéguez». Nov. 1822. quejas del sacerdote, pues no solamente había alterado el culto religioso, sino que los ingresos que esperaba por los responsos disminuyeron considerablemente. A esta huida por evitar levas, habría que añadir otro factor importante para la merma en las arcas de la Iglesia: la disminución de la producción agrícola, sobre todo de maíz y trigo, ${ }^{34}$ que a su vez impedía la recolección de diezmos y dotación de ofrendas para algunos sacramentos como el bautismo y el matrimonio.

Por otra parte, el gobernador Rojas también aplicó medidas impositivas a modo de préstamos forzosos de los principales comerciantes piuranos. Ante la negativa, procedía a desterrarlos o encarcelarlos, tal como sucedió a Girón, a Joaquín Arbaiza y a José Manuel Mañoz, del poblado de Sechura, que escribió desesperadamente al vicario Diéguez para intentar librarse del arresto en que se encontraba junto con otros vecinos del lugar. Los supuestos protegidos del vicario y del coronel Andrés de Santa Cruz estuvieron en la mira del gobernador, quien cometió atropellos contra sus bienes y personas. No es aventurado pensar que tanto los afectados como sus familias y amigos implorasen a Dios y a sus principales devociones por la pronta salida de la ciudad de Rojas y otros porteños. No en vano Mañoz recalcaba que «no hay uno que no esté temeroso con sus providencias, porque están viendo las que está apretando, y así es que no hay uno que viva tranquilo»; ${ }^{35}$ postura reforzada por el cura de Catacaos Fermín Seminario, que por el mismo tiempo se lamentaba diciendo:

Roxas cada día más déspota, y no hay uno solo que lo quiera bien, y solo las armas hacen sufrirlo; y así si el Congreso no nos mira con piedad quitándonos a este vicho, nos echaremos una soga al cuello para acabar de morir. $^{36}$

Los feligreses permanecieron ocultos hasta convencerse de la sustitución de Rojas por el piurano Gerónimo Seminario, debida a las variadas denuncias ante el gobierno central. En este contexto se percibe que, lejos de desear fervientemente la independencia, los grupos con menos poder adquisitivo asumieron funciones en la guerra presionados por las autoridades militares, de acuerdo a sus intereses o en defensa de su propia existencia. Como afirma el historiador Heraclio Bonilla (2001: 122-124), esto no hace más que mostrar los complicados comportamientos de estas clases bajas en un contexto en donde su adhesión estuvo supeditada al uso de mecanismos coactivos de reclutamiento, engaño y concesión coyuntural de ciertas exenciones.

Verificada la salida del gobernador Rojas, los piuranos clamaron a «Dios [...] por gefes a la similitud del General Santa Cruz» que, entonces, se encontraba de segundo general del Ejército del Centro, a quien deseaban que en todas sus acciones de guerra saliera «victorioso, librándonos de todo Porteño déspota». ${ }^{37}$ Esta rogativa personal muestra el

${ }^{34}$ AGN. CTD. Caja 2, correspondencia n. 8, carta 9, Huarmaca, 1822, fol. 1v.

35 Cfr. AGN. CTD. Nueva signatura. Caja 3. Doc. 1040. «Carta de J. M. Mañoz a Tomás Diéguez». Oct. 1822, fol. 1r-3v.

36 AGN. CTD. Nueva signatura. Caja 4. Doc. 1448. "Carta de Fermín Seminario a Tomas Diéguez». Oct. 1822, fol. 2r.

37 AGN. CTD. Nueva signatura. Caja 2. Doc. 615. «Carta de Ramón de Estrella a Tomás Diéguez». Nov. 1822, fol. 1r. 
apego de los parroquianos a un Dios misericordioso que, según su creencia, podía no solo librarles del mal gobierno sino también trocarlo por otro bueno y justo.

En conjunto, la situación conflictiva y la sensación de autonomía y libertad fueron aprovechadas no solo por las autoridades sino también por los mismos pobladores para alterar algunas costumbres religiosas a las que estaban obligados diariamente, como los rezos comunitarios, misas y catequesis dominical. Contribuían a ello su escaso adoctrinamiento, su temor a exponerse en las calles o el retorno a sus costumbres religiosas andinas. Al respecto, Juan José Martínez Álvarez de Noriega, capellán de Motupe, informa que el pueblo está tan perturbado por las revueltas y motines

qe casi no hay religión y es qe los qe antes llamábamos yndios y hoy hermanos, no hacen Doctrina, no oyen misa, no asisten a la Salve y están enteramente entregados a sus vicios y torpezas porque se hayan sin la menor sujeción, y apoyados de todos estos jueces parciales y rústicos... ${ }^{38}$

Ante lo cual había que tomar serias medidas desde el Legislativo para poner fin a tanta desviación. A la par que estas demostraciones impulsivas, hubo quienes prefirieron solicitar formalmente a la Iglesia algunos cambios en las tradiciones religiosas hispanas que significaban gastos excesivos para ellos, especialmente a causa de la escasez de trabajo y las múltiples contribuciones forzosas. Los pobladores de Colán, por ejemplo, que aún recordaban lo conseguido tras apoyar al ejército de Cochrane, presionaron a las autoridades eclesiásticas para la erradicación de la «obligación de Altares» de Semana Santa, consiguiendo que las

Parcialidades, por turno, hicieren en lo subcecibo dichos altares, correspondiendo uno a cada una de ellas, y siendo cinco con la de Forasteros, ésta quedase obligada a hacer las de las octavas que se celebren. ${ }^{39}$

En este caso se trató de alterar una costumbre religiosa muy importante y la autoridad cedió en aras de la libertad, reestructurando el mecanismo de la fiesta religiosa más relevante del calendario litúrgico. Este acontecimiento se convirtió en un buen precedente para que las demás comunidades se atrevieran a pedir una serie de cambios en las fiestas religiosas, porque, pocos días después, en vísperas de la celebración de la segunda fiesta más importante, el Corpus Christi, los mayordomos de la cofradía del Santísimo Sacramento de Catacaos solicitaron a Crisanto Gabino Calle su postergación para el primer domingo de agosto. Las razones con que sustentaron su pedido fueron la disminución de feligreses y los efectos negativos de las inundaciones que habían afectado la zona y que, en conjunto, redujeron al mínimo el dinero para costear los gastos. Las incesantes lluvias vividas en los meses de verano no solo afectaron las cosechas sino también la estructura arquitectónica de algunas capillas, lo que puso en riesgo la vida de los asistentes al culto; así ocurrió en Morropón, donde no podía celebrarse

38 AGN. CTD. Nueva signatura. Caja 3. Doc. 1090. «Carta de Juan Josef Martinez Alvares de Noriega a Tomas Diéguez». Nov. 1822, fol. $1 r-2 r$.

39 AGN. CTD. Nueva signatura. Caja 1. Doc. 455. «Carta de Manuel a Tomás Diéguez». Mar. 1821, fol. 1 r. misa a causa de esta inseguridad. ${ }^{40}$ Con todo, la argumentación de los mayordomos insistía en la postergación de la fiesta religiosa a causa de la insuficiencia de dinero para comprar cera, consecuencia de la pérdida de todos sus productos y, también, por la huida y temor de muchos parroquianos. ${ }^{41}$ Sin embargo, el pedido fue rechazado por el vicario Tomás Diéguez, de manera que la fiesta hubo de celebrarse en su día, lo cual incrementó la presión sobre los devotos y exprimió al máximo sus recursos, a pesar del conocimiento de sus penurias por parte de la autoridad eclesiástica.

Poco después, esta petición se unió a las ideas del gobernador de Catacaos, quien repetía a los alcaldes que no pagasen ninguna ofrenda ni en casamientos ni en las fiestas religiosas. ${ }^{42}$ El tema de las ofrendas era bastante delicado y había generado una serie de altercados por la reticencia del grupo indígena a otorgarlas en misas, bautismos, matrimonios y entierros. Según la normativa, estas eran absolutamente voluntarias, pero la costumbre había establecido unos montos más o menos precisos en cada caso. Conocedores de la ley, y mucho más en un ambiente de autonomía y libertad, las autoridades políticas decidieron intervenir en este rubro a favor de sus comunidades indígenas, provocando serios desencuentros con los representantes eclesiásticos. Ante tal forma de pensar, el encargado del curato envió una misiva al vicario Tomás Diéguez en la que censuraba la intromisión del gobierno en asuntos netamente religiosos, provocando con ello alteraciones, murmuraciones y actos violentos en el pueblo. Resulta claro que esta intrusión, que afectaba directamente a la economía de la Iglesia, no acarreaba adhesiones por parte del clero a la independencia lograda y ensanchaba aún más la brecha entre Iglesia y Estado.

Desde el gobierno central, Bernardo de Monteagudo presionó a la jerarquía de la Iglesia para que, haciendo uso de su influencia en los fieles y utilizando todos los métodos necesarios, lograse inducirlos a apoyar la causa patriota. En una carta al gobernador eclesiástico de Lima, Francisco Javier Echagüe, recalca que «Espera que [...] todos los eclesiásticos del Perú ejerciten su patriotismo y su celo trabajando por la justicia, que es una de las obras más gratas a Dios» (Martínez 1992: 104). Este tipo de órdenes emitidas, unido a las interpretaciones personales de cada autoridad política, desencadenaron imbricadas situaciones que herían susceptibilidades y que, finalmente, ponían a los parroquianos en la disyuntiva de tomar partido por uno $u$ otro litigante. En realidad, el asunto partía de cuestiones meramente simbólicas que evidenciaban el poder de uno sobre otro frente a los patriotas-feligreses, pero en el fondo se entendía como una intrusión en el ámbito religioso, custodiado por más de dos décadas por la jerarquía de la Iglesia.

El pueblo de Catacaos se prestaría nuevamente como escenario de disputas y altercados entre ambas autoridades, es decir, del cura contra los representantes del Ayuntamiento. El grupo de cabildantes, asumiendo su

40 AGN. CTD. Caja 1, correspondencia n.o 4, carta 17, Piura, 1823, fol. $1 r$.

41 AGN. CTD. Caja 2, correspondencia n. 8, carta 18, Catacaos, 1823, fol. 2 r-v.

42 Cfr. AGN. CTD. Caja 2, correspondencia n. ${ }^{\circ}$, carta 19, Catacaos, 1823 , fol. 1r-v. Véase también en carta 31, Catacaos, 1823, fol. 1r. 
preeminencia política, esperaba al sacerdote en la puerta de su casa para acompañarlo hasta la Iglesia a celebrar Misa. Si demoraba, uno de los representantes hacía notar la tardanza al cura, que, lejos de pedir disculpas, enérgicamente los despedía «mandándoles que fuesen afuera a esperarle». Con este acto despreciativo insultaba a estos peruanos que, días antes, habían recibido tratamiento de Señorías por las autoridades políticas y, por ende, esperaban lo mismo de la eclesiástica. Los privilegios obtenidos por el cabildo en el plano político-social le permitieron pensar que podía hacer las veces de escolta de pastores, sin prever que esto podía interpretarse como vigilancia e intrusión. El acompañamiento se aplicó también en las ceremonias fúnebres que convergían en la misa de cuerpo presente y en la sepultura, provocando que fuese considerado un acto indecente pues su función debía restringirse a quedarse en las bancas del templo. Por último, el conjunto de munícipes no necesariamente seguía a su presidente y por ello dejaba de entregar las respectivas ofrendas, lo cual ahondaba aún más las rencillas con el sacerdote al disminuir las arcas de la iglesia. ${ }^{43}$

Cuando los feligreses tomaban postura a favor de la autoridad política, eran los eclesiásticos los que levantaban la voz de protesta y buscaban frenar las conductas lascivas expresadas en escritos y en actos violentos. A veces las medidas inmediatas tomadas por los curas eran las de ausentarse del curato y refugiarse en otros cercanos. En Sechura, por entonces, se experimentó una situación que refleja lo antes dicho: el presbítero Francisco Javier Palacios tuvo serios problemas con los pobladores, quienes habían publicado bandos contra su persona y a favor de su teniente gobernador José María Mañoz. Dicho acoso provocó que abandonara la iglesia y buscara por asilo el pueblo de Catacaos, con la única intención de salvar la vida y de restablecerse de sus "accidentes». ${ }^{44}$ Cabe resaltar, por otra parte, que meses atrás algunos indios, instigados por el procurador Eugenio Temoche, habían tenido altercados con este teniente gobernador que luego defenderían porque se había adelantado a "darle la licencia al Maromero» (sic), orden que les correspondía a ellos. Su violenta actuación les costó una denuncia formal y para evitar castigos buscaron el perdón de Mañoz. ${ }^{45}$

En síntesis, esta convivencia inicial de gobierno republicano con la Iglesia no siempre fue cordial ya que aquel echó mano de esta y de su prestigio para lograr sus objetivos, pero, a la par, también trató de ejercer sobre la Iglesia un dominio que se excedió en algunas autoridades políticas.

\section{MOTIVOSYMUESTRAS DE DESENCANTO ANTE LAINDEPENDENCIA}

A pesar del optimismo e ilusión nacidos en la proclamación de la independencia en Piura y en otros partidos, corroboramos - al menos en los primeros años - una sensación de desencanto entre algunos miembros del clero y de las cofradías, y también entre extranjeros, indios y mestizos.

43 AGN. CTD. Nueva signatura. Caja 2. Doc. 623. «Carta de Ramon Estrella a Tomas Diéguez». Jun. 1823, fol. 1r-v.

44 AGN. CTD. Nueva signatura. Caja 3. Doc. 1244. «Carta de Francisco Xavier Palacios a Tomas Diéguez». Feb. 1823, fol. 1r-v.

45 AGN. CTD. Nueva signatura. Caja 3. Doc. 1039. "Carta de José María Mañoz a Tomas Diéguez». Mar. 1822, fol. 1r.
Pasados los tiempos de festejo y de celebración, como ya hemos mencionado, comenzaron a vivirse momentos de intranquilidad por la prolongada presencia del ejército patriota, los donativos forzosos y confiscaciones y por la proliferación de ideas ilustradas y liberales. Analicemos brevemente cada uno de estos tres factores, empezando por el último.

La libertad de imprenta - cuyas raíces habían calado en el suelo patrio- fue una razón que provocó resentimiento en algunas autoridades eclesiásticas por otorgar licencia a libros ilustrados y liberales que contenían enseñanzas consideradas como irreligiosas. Los clérigos criticaban duramente que «en poco más de un año de ateísmo [se han] visto los pésimos frutos que ha introducido» ${ }^{46}$ el Estado en la persona de su ministro Monteagudo. Estas opiniones y resentimientos con toda seguridad fueron parte esencial de sus sermones, de los consejos en los confesonarios, de las pláticas en el adoctrinamiento y en cualquier oportunidad a su alcance.

Lamentablemente para los piuranos de entonces, la salida del coronel Rojas no significó el término de los reclutamientos, pues en la sierra peruana seguía emplazado el ejército realista preparando la batalla final. Por tanto, el mecanismo continuó durante los meses consecutivos sin respetar la exención del ejercicio militar a los casados y los hijos de viudas. He aquí la segunda razón de descontento, pues tal atropello produjo una serie de lastimeros ruegos, tanto a los seres celestiales como a las autoridades terrenales, puesto que algunas autoridades políticas y religiosas tenían cierta influencia para sacar del cuerpo militar a los mal enganchados. La piurana Baltasara Segunda Zapata es un caso representativo de lo que seguramente vivieron decenas de madres tras la captura de sus hijos enviados a engrosar las fuerzas militares. Angustiada y desesperada, agradece al vicario Tomás Diéguez por haber librado del rigor de las armas a sus dos hijos, pero pide encarecidamente que «los saque de la filiación soldadesca para algún consuelo mío». Insiste en que se vale del «Todo Poderoso y de la Virgen Santísima, su Madre y de pecadores también, a quienes elevo mis súplicas y tibias oraciones»; y recalca su plena confianza en Dios para que el vicario pueda rescatar a sus dos hijos. ${ }^{47}$

El malestar se extendió y agudizó cuando los oficiales y soldados reforzaron las levas en varios pueblos costeños del partido de Piura, de tal manera que, en marzo de 1823, se hizo necesario que el mismo procurador de Catacaos viajase a Trujillo a poner una demanda contra los miembros del ejército por «querer sacar gente del pueblo con muchas amenazas» y sin obedecer las órdenes formales que mandaba al respecto el "Soberano Congreso". ${ }^{48}$ Un mes después, la llegada de catorce individuos a la ciudad de Piura para organizar dos escuadrones, generó nuevas huidas de los pocos hombres útiles que aún quedaban en el lugar.

Cabe resaltar que en el cuerpo militar se tuvo cierta consideración con los hombres pertenecientes a grupos de

\footnotetext{
46 AGN. CTD. Caja 2, correspondencia n.o 7, carta 32, Trujillo, 1822, fol. $1 r$.

47 AGN. CTD. Nueva signatura. Caja 4. Doc. 1639. «Carta de Baltasara Segunda Zapata a Tomás Diéguez». Mar. 1823, fol. 1r-v.

${ }^{48}$ AGN. CTD. Nueva signatura. Caja 4. Doc. 1638. "Carta de Alexo Zapata a Tomás Diéguez». Mar. 1823, fol. 1r.
} 
poder que, si bien permanecían en la reserva, no necesariamente eran enviados al campo de batalla a exponer su vida. El grupo social que padeció los rigores de la guerra fue el indígena, al constituirse en verdadera «carne de cañón» en este tiempo. Como ya explicamos párrafos atrás, las levas fueron constantes en el partido de Piura aprovechando las reuniones del común de los indios en los domingos o días festivos, lo cual generó una despoblación evidente en varias ciudades y pueblos piuranos. Esto le granjeó al nuevo gobierno la fama de despótico y «por esta causa la opinión de la independencia ha decaído en su mayor parte, que admira no verse la que hubo en sus principios que fue tan poderosa». Esta opinión de Mariano García, un piurano perteneciente al grupo de poder de entonces, se corrobora en la misiva que envió al vicario Tomás Diéguez en abril de 1823 , en la que enfatiza que «si los mandones hubiesen sido sagaces, prudentes y benignos, castigando solo a los delincuentes no habría decaído la opinión ${ }^{49}$

La última causa de decepción con la independencia estuvo centrada en el cúmulo de donativos forzosos y confiscaciones que ejerció el Gobierno central en personas e instituciones religiosas. Estas acciones atentaron contra los intereses económicos de la Iglesia y por ende enfriaron idealismos iniciales para provocar en cambio múltiples sinsabores de no pocos ciudadanos y eclesiásticos.

La política de donativos fue una constante que se agudizó en 1811 cuando varios súbditos se quejaron por tener que entregar bienes materiales en auxilio de la Madre Patria que deseaba sacudirse el yugo francés. Se retomó durante las guerras de la independencia, cuando desde ambos bandos se exigían aportes a la población que dejaron exhaustas sus arcas.

Creemos que las instituciones religiosas fueron las más afectadas porque tanto el virrey como el gobierno republicano tomaron parte de la plata labrada y objetos de oro que constituían su patrimonio. El arzobispo Las Heras sería uno de los principales defensores del tesoro de la Iglesia, si bien, paulatinamente, hubo de ir entregando al Estado hasta sus objetos personales. Por su parte, José de la Riva Agüero, en Lima, mandó que los prelados de los conventos religiosos entregaran una lista de todos los europeos refugiados en sus conventos, en la que se hiciera constar su patria, sexo, edad y opiniones respecto a la independencia, además del número de alhajas, especies y dinero que se hallasen depositados en los conventos (pertenecientes o no a los refugiados). ${ }^{50}$

Para el caso piurano, en tiempos de San Martín se estableció la Junta de Arbitrios con el objetivo de proporcionar medios económicos para el sostenimiento del ejército que incursionaría en las provincias de Loja y Cuenca en apoyo de su independencia. La mencionada Junta estableció contribuciones repartidas por los distintos pueblos, considerando que la cantidad erogada tenía que ser de 4.790 pesos mensuales. ${ }^{51}$ Determinó, además, que el sacrificio de cada ciudadano sería el fruto de un solo día al mes, en

49 AGN. CTD. Caja 2, doc. 700, Piura, 1823, fol. 1r-v.

50 AGI. Lima 800. Colección de bandos publicados...p. 37.

51 De este monto, la Iglesia de Piura debía recolectar 1000 pesos, la de Ayabaca 400 pesos, las de Catacaos, La Punta, Yapatera, Morropón y Huancabamba 300 pesos cada una y las demás por debajo de esta cifra hasta un mínimo de 50 pesos que entregaría la parroquia de Congoña. tanto que los curas, hacendados y comerciantes habrían de contribuir con 10 pesos; el jornalero solo con 2 reales (Gutiérrez 2004: 367). Como estas primeras disposiciones eran bastante generales, provocaron dudas acerca de si la contribución era forzosa, la edad a partir de la que se debía contribuir, y si debían dar donativos individuos como los hijos de familias onerosas en edad de trabajar, las mujeres solteras y viudas que tuviesen algún caudal, los eclesiásticos y sirvientes y los pobres de solemnidad. ${ }^{52}$ Para aclarar estas dudas se publicaron en las puertas de iglesias y parroquias un conjunto de normas básicas respecto del pago, de modo que los contribuyentes de 18 años en adelante aportarían 1 peso mensual por cada 1000 pesos de capital que poseyeren (bienes muebles, esclavos, casas, haciendas, tierras propias, efectos mercantiles, etc.). Nadie entregaría más de 10 pesos. Quienes tuvieren capital menor de 1000 pesos habrían de contribuir con 4 reales mensuales; los maestros de tiendas públicas 4 reales. Por su parte, las mujeres sin capital estarían exentas de este pago; teniéndolo, contribuirían como los varones. Previendo las resistencias, se estipularon castigos y multas contra los omisos e infractores, disponiéndose los primeros cobros para los meses de febrero y mayo de 1822 (Gutiérrez 2004: 368). Cada miembro del clero, por su parte, debía pagar un cupo mensual teniendo en cuenta sus proporciones porque ya habían padecido atropellos de los jefes militares y municipalidades, que para su desesperación y desasosiego les habían exigido exacciones extraordinarias. Para paliar esta problemática se le informó a la Junta que

\begin{abstract}
el clero no tendría que sufrir otro género de contribuciones y por consiguiente cualquier autoridad que quiera imponerle otras nuevas deberá haber recibido para ello una orden especial del Gobierno a quien espondría si no la tuviese a sufrir la nota de una mala fe muy injuriosa y de haber burlado con ofrecimientos bagos a una corporación respetable. ${ }^{53}$
\end{abstract}

De manera general, las recaudaciones atentaban directamente contra los bienes personales y, por supuesto, forjó serios malestares y enojos reflejados en cartas como la enviada por el ya conocido José María Mañoz, en noviembre de 1821, en la que se queja del oficio enviado por los señores de la Junta en que le «exigen cincuenta pesos de donativo forzoso que, aunque me vendan no los balgo, que bien lo conocen ellos, y [...] así les contestaré mañana». Para recalcar su pobre situación económica, indica que no hay en su casa productos que valgan la pena, porque son tan escasos que no alcanzan ni para comer. Por la personalidad del encargado para la recolección en el pueblo de Sechura, él pensó que no recogería «ni quarenta pesos por mes porque me parece que no ha nacido para hacer exijir ni para que los exijan, sino para guardar aun lo ajeno». ${ }^{54}$

Otros encargados de recaudar fueron los curas que, aprovechando misas, ceremonias y fiestas religiosas,

$\overline{\text { Cfr. Archivo Regional }}$ de Piura (ARP). Gobierno Político, Leg. 12, Año 1822 , f. 2 r.

52 Cfr. AGN. CTD. Nueva signatura. Caja 3. Doc. 1038. "Carta de Joseé María Mañoz a Tomás Diéguez». Feb. 1822, fol. 1r.

53 AGN. CTD. Nueva signatura. Caja 3. Doc. 1269. "Carta de Carlos Pedemonte a Tomás Diéguez». Jul. 1824, fol. 1r.

54 AGN. CTD. Nueva signatura. Caja 3. Doc. 1036. «Carta de Jose María Mañoz a Tomás Diéguez». Nov. 1821, fol. 1r. 
además de solicitar las ofrendas y diezmos se veían obligados a pedir estas contribuciones extraordinarias. Carlos Cáceres, de la doctrina de Huarmaca, por ejemplo, comenta al vicario Tomás Diéguez que «los $20 \mathrm{p}^{\mathrm{s}}$ para la Patria qe voy a entregar a Dn Juan José Carrasco [...] qe he podido colectar de responsitos y otras entradas se los lleva la Patria, quedándome sin medio" para sobrevivir, razón por la que quería dejar el curato (aunque no podía, porque los indios no le proporcionaban los animales necesarios temiendo que no regresara al pueblo). ${ }^{55}$ Como observamos, no fue fácil la tarea de recaudación ni para los recaudadores ni mucho menos para los desfavorecidos indios, que vieron reducidos al mínimo sus precarios bienes y, en consecuencia, estuvieron siempre predispuestos a levantar la voz de protesta en acciones violentas, tanto que en algunos poblados como Sechura urgió la presencia de soldados para poder acallarlos. ${ }^{56}$

De las 25 iglesias consignadas en el plan de contribuciones, solo cinco cumplieron con la orden establecida: Ayabaca, Huancabamba, Chalaco, Sondor y Cumbicus; ${ }^{57}$ por lo que se hizo imprescindible que el vicario de Piura, en mayo de 1823, enviara oficios a los distintos curatos para que realizaran «misa de Gracia i juramento, juntamente con donativo ${ }^{58}$ logrando de Catacaos la suma de 4 pesos por este concepto.

Dos meses después, el Senado envió un comunicado a los diferentes pueblos obligándolos a hacer algunos sacrificios económicos para sellar la independencia, recalcando que el objetivo de los pueblos era sostenerla por su unión, tranquilidad y sacrificios realizados (Gutiérrez 2004: 398).

Cuando Simón Bolívar asumió la dirección del gobierno del Perú, decidió tomar prestada la plata labrada de las iglesias para paliar los gastos que demandaba la campaña libertadora. En respuesta a este pedido, algunas instituciones religiosas piuranas entregaron lámparas, frontales, candelabros, mallas, pilares, gradillas, arcos, centelleros, potencias, incensarios, atriles, arañas y otras piezas de oro y plata pertenecientes al Santísimo Sacramento y a algunas advocaciones de la Virgen (Ramos 1973: 64). En Trujillo y en otras ciudades pasó exactamente lo mismo, pues, a decir del presbítero Manuel José de Arrunátegui, en esa ciudad se habían «barrido todas las alhajas de Yglesias, sin mas ecepcion que la que $U$ me puntualiza de Custodia y vasos sagrados». Ante tal usurpación hubo devotos que compraron piezas que servían de adorno a los principales altares de su veneración y las guardaron en sus casas para colocarlas en los días de fiesta y luego volverlas a custodiar en secreto. ${ }^{59}$ En esta línea, tanto sacerdotes como feligreses se resistieron a entregar el patrimonio de sus respectivas iglesias por más que estuvieran a favor de la independencia; por el contrario, el malestar se fue agudizando de tal manera que llegó a convertirse en recelo y desilusión.

55 AGN. CTD. Nueva signatura. Caja 1. Doc. 180. «Carta de Carlos Caseres a Tomas Diéguez». Nov. 1821, fol. 1r.

56 Cfr. AGN. CTD. Nueva signatura. Caja 3. Doc. 1036. «Carta de Jose María Mañoz a Tomás Diéguez». Nov. 1821, fol. 1r.

57 Cfr. ARP. Gobierno Político. Año 1822, Leg 12, exp. 218.

58 AGN. CTD. Caja 2, cuaderno № 8, carta 19, Catacaos, 1823, fol. 2r.

59 Cfr. AGN. CTD. Nueva signatura. Caja 1. Doc. 117. «Carta de Manuel Jose de Arrunátegui a Tomás Diéguez». Ago. 1824, fol. $1 r$.
Esta manera de actuar iba contra lo establecido por Bolívar, en julio de 1824, cuando recalcó que en cada iglesia solo debía quedar

un incensario, la custodia y los vasos sagrados, sin que sirva de objeción el que algunas alhajas de las que han dado pertenezcan a devotos particulares, pues estos, en el momento de donación [...] ya no tienen dominio sobre ellas [...] y debe saberse indispensablemente y bajo la más seria responsabilidad a el Cura o Mayordomo que intente ocultarla (Ramos 1973: 64).

Las justificaciones más frecuentes para no entregar los objetos sagrados fue su pertenencia a personas particulares y su utilización en el culto y en las fiestas religiosas. Ninguna de las dos fue válida para el Gobierno, que solo permitió la permanencia de los objetos estrictamente necesarios para los rituales. Para colmo de males, se encargó a los mismos curas la comisión de practicar la entrega, llevándose a cabo una nueva requisa de plata el día 16 de agosto en presencia de todos los interesados de la Matriz y de sus cofradías.

Las confiscaciones realizadas de marzo a agosto de 1824, en la provincia de Piura, que aparecen consignadas en la Gaceta del Gobierno del Perú, ascendieron a 1466 marcos de plata valorizados en 8829 pesos y 5 reales, y 1132 castellanos de oro cotizados en 2265 pesos y 6 reales (Gutiérrez 2004: 400-401).

Tras la victoria del ejército patriota en la batalla de Junín (6-VIII-1824), y dispuesto a partir hacia Ayacucho, se celebró una misa de acción de gracias en la catedral de Trujillo, para encomendarlo y rogar por la segunda victoria. El arcediano Pedemonte estuvo encargado del sermón, que luego, por orden del Gobierno, se imprimió y repartió a las distintas vicarías. A Tomás Diéguez le remitieron «un número de exemplares para qe los reparta entre los curas de su Provincia» con la intención de seguir con las rogativas públicas en cada curato. ${ }^{60}$

Como queda verificado en este rápido recorrido de donaciones y préstamos de personas e instituciones religiosas durante más de tres años, el esfuerzo exigido fue constante y sustenta la hipótesis del desapego y distanciamiento que se apoderó de los miembros que defendían la independencia, mucho más cuando se empiezan a aplicar una serie de medidas como multas, encarcelamientos, destierros, prohibición de profesiones religiosas a menores de 30 años, suspensión del ejercicio de sus funciones a los curas españoles (Vargas 1945: 192), cierre de noviciados y monasterios, entre otras. Este conjunto de disposiciones creó un ambiente tan enrarecido que, sin lugar a dudas, desilusionó a todo aquel que fue afectado directa o indirectamente.

\section{FUENTES}

Helguero, Joaquín de. 1984. Informe económico de Piura 1802. Piura: UNMSM, CIPCA.

Mikhailovicht, Vasilii. 1971. "Lima y Callao en 1818». En Colección Documental de la Independencia del Perú (CDIP), Tomo XXVII, Vol. 1, 145-173.

60 AGN. CTD. Nueva signatura. Caja 3. Doc. 1317. «Carta de Manuel Ramirez de Arellano a Tomas Diéguez». Set. 1824, fol. $1 r$. 
Ramos, Enrique. 1973. Documentos Históricos. Piura: Concejo Provincial de Piura, Edición de la Inspección de Cultura en la XXI Semana de Piura.

\section{BibLIOgRAFíA}

Barros, Diego. 1999. Historia General de Chile. Tomo XII. Santiago de Chile: Editorial Universitaria S. A.

Bonilla, Heraclio. 2001. Metáfora y realidad en la Independencia en el Perú. Lima: IEP.

Gutiérrez, Julissa. 2004. «La Independencia». En Historia de Piura, dirigido por José Antonio del Busto, 319-388. Piura: Universidad de Piura - Municipalidad Provincial de Piura.
Hernández, Elizabeth del Socorro. 2005. La élite piurana ante la Independencia del Perú: la lucha por la continuidad en el tránsito hacia la República. Tesis doctoral, Universidad de Navarra.

Nieto, Armando. 1969-1971. "Notas sobre la actitud de los obispos frente a la Independencia peruana (1820-1822)». Boletín del Instituto Riva Agüero 8: 363-373.

Rosas Navarro, Ruth Magali. 2013. Mentalidad y discurso religioso en la transición hacia la independencia en el norte del virreinato peruano: El Partido de Piura. Trabajo Fin de Máster, Huelva, Universidad de Huelva.

Rosas Navarro, Ruth Magali. 2019. Religiosidad en el Partido de Piura durante el proceso de la Independencia. 1780-1821. Tesis doctoral. Universidad de Huelva. http://hdl.handle.net/10272/16525.

Vargas, Rubén. 1945. El Episcopado en los tiempos de la Emancipación Sudamericana. Buenos Aires: Huarpes. 